\title{
An Analysis of Corporate Ethical Code Studies: "Where Do We Go From Here?"
}

Betsy Stevens

\begin{abstract}
The dramatic increase in the number of corporate ethical codes over the past 20 years has been attributed to the Watergate scandal and the Foreign Corrupt Practices Act. Ethical codes differ somewhat from professional codes and mission statements; yet the terms are frequently interchanged and often confused in the literature. Ethical code studies are reviewed in terms of how codes are communicated to employees and whether implications for violating codes are discussed. Most studies use content analysis to determine subjects in codes. Little information is available about how codes are communicated, whether they are accepted and used by employees, and whether they affect employee/corporate behavior. More research on ethical codes is needed to answer some of these questions.
\end{abstract}

Incidents surrounding Watergate and passage of the Foreign Corrupt Practices Act in 1977 have been credited to the tremendous growth and popularity of corporate ethical codes. Following the 1975 Watergate scandal, a number of corporations were implicated in illegal or questionable acts and calls for government regulation received increased support. Smarting from criticism and low public opinion, a number of corporations wrote codes of ethics to betoken a new, more moral image and to redefine their values.

This increase in codes, noted by Cressey and Moore (1983), Becker and Fritszche (1987), Berenbeim (1987), Brooks (1989) and Rogers and Swales (1990) also received attention in major business newspapers. In a Wall Street Journal article, Bennett $(1988$, p. 17) remarked, "Formal ethical codes are hot

Betsy Stevens is a lecturer at the University of Michigan School of Business Administration. She received her Ph.D. in 1992 in organizational communication. Her research interests are corporate ethical codes and human resource issues such as employmentat-will. these days. Companies without them are scrambling to commit corporate values to paper." The proliferation of corporate ethical codes over the past 20 years has attracted the interest of scholars who have primarily used content analysis to discover subjects in these codes. The studies have been most useful in determining the factual subject matter found in codes and the extent to which the same subjects occur in different codes.

At the same time we might ask "Have we learned what we need to know about corporate codes?" Certainly the content analyses have yielded rich information about subject matter, but can they answer our questions about corporate codes in terms of how they are communicated to employees and whether they are truly effecrive? This paper first attempts to present some definitions of ethical codes, professional codes and mission statements, then reviews the existing ethical code literature, and finally suggests some new directions for ethical code research.

\section{Definitions}

Corporate ethical codes differ somewhat from professional codes and mission statements, yet the terms are frequently interchanged by corporations and occasionally confused in the literature (Pearce and David, 1987). Lines between these genres are not really clear cut. Moreover, few code studies have undertaken the task of defining corporate codes. Cressey and Moore (1983) moved toward defining ethical codes when they excluded documents from their study which did not "address themselves to activities which reach beyond the firm itself" (p. 55). A somewhat basic definition is offered by Berenbeim (1987) - "A code of ethics is a major vehicle for 
stating ethical principles" (p. vii). Pitt and Groskaufmanis (1990) take it further by using "corporate codes of conduct" and "corporate codes" as terms to designate "any written statement of ethics, law or policy ... delineating the obligations of one or more classes of corporate employees" (1559, \#1).

We might first attempt to define corporate ethical codes through description. They are written documents, ranging in length from one paragraph to more than fifty pages, which are intended to impact employee behavior. Firms frequently attempt to manage and articulate ethics through these messages which are designed for both internal and external audiences. Codes, then, are managerial tools for shaping change. They often demand from employees higher standards of behavior than required by law. A code may be part of a personnel policies manual, which many courts interpret as a legal contract between employee and employer, or it may be a separately issued document which stands alone. Some have affidavits of understanding or oaths which require the employee's signature and others do not. Most importantly, they are messages through which corporations hope to shape employee behavior and effect change through explicit statements of desired behavior.

Professional codes articulate the goals and beliefs for groups of professionals by which individual practitioners can be guided. These frequently require higher standards than are legally mandated and have evolved in response to social, environmental and economic demands.' Frankel (1988, p. 110) noted that a profession's code of ethics is "the most visible and explicit enunciation of its professional norms ... and embodies the collective conscience of a profession." Additionally, Frankel argued that professional codes could be classified as aspirational, educational, or regulatory. The first classification states ideals to which practioners should strive, the second enhances understanding through commentary and the third provides a detailed set of rules.

Mission statements attempt to address strategic management issues. They define the "fundamental unique purpose that sets a business apart from other firms of its type and identify the scope of businesses' operations in product and market terms" (Pearch and David, 1987, p. 109). While they differ from corporate ethical statements by more directly addressing strategic planning and bottom line issues, mission statements frequently resemble ethical codes when they incorporate more metaphysical concepts such as values and ideals. Distinctions between ethical codes, professional codes, and mission statements often become blurred and sometimes overlap. For example, Rogers and Swales (1990) describe the Dana Corporation code as "a hybrid code for it is both a credo or mission statement and an outline of fundamental principles and policies for Dana Corporation and Dana employees" (p. 297).

Corporate ethical codes have roots in early professional codes. While a number of ethical codes were written in the early part of this century (i.e., the J. C. Penney code in 1913), most came much later. Professional codes, however, were common in the 1920's. An early collection of professional ethical codes (Heermance, 1924) includes codes of the National Association of Straw Hat Manufacturers, the National Association of Peanut Butter Manufacturers, the National Confectioners Association of the United States, a collective of candy makers. These associations reflect the pre-corporate status of many small companies which existed to produce single products.

The morals and values articulated in these codes embody the prevailing ethic of the time. For example, The National Confectioners Association of the United States disparaged games of chance in candy packaging by arguing "they encourage and develop the gambling habit in children, are injurious to their morals and ... are a menace to the future development of the industry" (Heermance, p. 119).

Ethical codes exist, in part, because corporations are held legally accountable for the actions of their employees. While corporate criminal liability is a 20 th century phenomena, it is based on the notion of respondeat superior: "Let the master answer" (Black, 1983, p. 681). This principle from common law holds the head (master) liable for illegal or wrongful acts of his servants. From this has emerged the doctrine holding the corporation responsible for the actions of its employees. In addition to responsibility, punitive damage assessment has a long history dating back to the Middle Ages (Pitt and Groskaufmanis, 1990). Corporate codes have been constructed partly as a defense against respondeat superior; however they do not always get the company off the hook. Courts have ruled that instructions to employees do not necessarily relieve the organization of responsibility 
for employee wrongdoing (Pitt and Groskaufmanis, p. 1560). A corporation can find itself held doubly responsible for employees misconduct and also for demonstrating it has successfully communicated appropriate behavioral standards to employees. Thus, the transmissional aspects of corporate ethical codes - how they are communicated to employees - are significant both in terms of legal expectations and in communicating corporate cultural expectations.

Some ethical codes are little more than legal barriers and self-defense mechanisms; others are intended to influence and shape employee behavior. In either event the impact of these codes as messages is an important concern. Whether a code can influence organizational change or successfully articulate elements of a corporate culture depends upon its effectiveness as a message. Thus, it is important to examine these codes in light of how their messages are communicated to employees.

Ethical codes studies were reviewed using the following two questions: (1) In what manner are the codes communicated to employees? This involves examining language choice and tone, particularly regarding requests or demands for compliance. (2) To what extent is the code enforced and implications for violating the code discussed? This addresses whether the code spells out what can bappen if the employee violates the code. What procedures will be invoked if the code is not followed? Will the employee be terminated? Answers to these questions may reveal whether the intent behind the code is self-protection, an attempt at promoting ethical leadership or management of a public image.

\section{Review of ethical code studies}

Corporate ethical code studies to date have either focused on individual codes (i.e. Rogers and Swales, 1990) or primarily used content analysis to address subject matter in the codes. White and Montgomery (1980) performed a content analysis on 30 codes obtained from CEO's in the Fortune 1000 and a random sample of 1000 members of the Financial Executives Institute. They listed 36 possible subjects ranging from a general statement of ethics and philosophy to insider trading. Conflict of interest was the most commonly addressed subject (73\%) followed by employees' responsibility to comply with federal laws (67\%) and misuse of corporate assets (67\%). They found an overall lack of consistency of subject matter which they attributed to inconsistency among the corporations. Most firms required officers and key employees to periodically sign the code, but only about $25 \%$ required other employees to sign.

Their study does not address the manner in which codes were communicated or include information about tone or format, except to describe styles as ranging "from formal and legalistic to nearly conversational" (p. 86). Additionally they concluded that some codes of conduct are "carefully constructed, thoughtful, and packaged in a manner suggesting they are intended to be read and understood." Others, they argued, were "haphazard in design, superficial in content, and are presented in a fashion which clearly does not encourage serious reading or facilitate understanding" (p. 86). They attributed these differences to managerial attitudes toward the codes. Regarding enforcement, they found that $83 \%$ of the organizations had administrative procedures to enforce the codes, but provided no further information about how enforcement might occur or implications for violating the codes.

Chatov (1980) categorized the content of 281 corporate codes into 12 broad ethical dimensions. Extortion, gifts, and kickbacks led the list of prohibited employee behaviors followed by conflict of interest, illegal political payments, violation of laws in general, use of insider information, and bribery. Chatov concluded that U.S. corporations agree upon which areas of employee misconduct cause the greatest concern. He does not discuss how codes are communicated except to note that in forbidding extortion, gifts and conflict of interest, they used "strong language" to deter these behaviors and observed that some codes "express moral standards in very personal terms" exhorting employees not to do anything they would not tell their spouse or not want to see in a newspaper (p. 24).

Cressey and Moore (1983) performed a content analysis on 119 corporate conduct codes on file with the Conference Board in New York City and found that conduct against the firms was discussed more frequently than conduct on behalf of the firm. Integrity of financial books and records was discussed less than half the time while about $50 \%$ of codes mentioned relations with competitors. Again, 
conflict of interest was the most frequently mentioned subject. Cressey and Moore found that the codes were mostly concerned with unethical behavior which might decrease profits and concluded that the codes exhibited a weak commitment to social responsibility. Like White and Montgomery, they found that executives held diverse views on the ethical importance of most policy areas.

Nearly all of the codes were grounded in some type of authority - "precepts, tenets, or principles" (p. 59) seemingly to legitimize the code. There was no discussion of how the codes were communicated, or if a CEO personally endorsed the code; however, they do focus extensively on employee sanctions for violating the codes and conclude that the codes are weak in following through with reprisals. They found that two thirds of the codes referred questions about the code's provisions to other sources which indicates the code was not seen as the final word. Regarding enforcement and implications for violators, they tell us only that $75 \%$ of codes contained information on compliance and most codes were enforced by upper management as opposed to management by personal integrity or by regulation through an outside agency. About 50\% had an affidavit of compliance or understanding which required a signature.

Sanderson and Varner (1984) analyzed 39 codes from the top Fortune 500 companies for content, organization, purpose, enforceability, and format. They found that $75 \%$ of content was related to complying with federal laws. Seventy percent of the codes addressed conflict of interest, $72 \%$ dealt with political contributions, and 59\% addressed customers, accuracy of accounting records and antitrust issues. The authors noted that "most of the codes consist mainly of rules based on laws" (p. 29).

Sanderson and Varner addressed the question of how the codes are communicated by assessing the readability of codes and determining the intended reader. They concluded that most codes were addressed generically to "all employees" and suggested that firms have separate codes for management and nonmanagement personnel. The wisdom of such a move is questionable as it invokes the concept of a double standard.

Using the Flesch test, ${ }^{2}$ to measure reading difficulty, they found that 22 codes were "very difficult" and 16 were" "difficult." It seems fair to question how many employees would actually read an ethical code which was hard going unless a signature was required. Sanderson and Varner offer the only comments on format. They observed that most codes were presented as small booklets ranging from 10 to 25 pages in length.

Regarding the second question of code violations, Sanderson and Varner indicated that only about $50 \%$ contained information as to how the code would be enforced. They observed that the language of enforcement was general and nondescriptive in codes which discussed enforcement and seemed to conclude that these were not effective.

A Conference Board survey of 300 international senior executives revealed that $76 \%$ of the respondents indicated their firm had an ethical code (Berenbeim, 1987). While language and tone for the codes were not summarized in any way, comments from executives regarding distribution and communication are included in this study.

One ethics program director noted, "The person the individual works for is in the best position to convey this (ethical code) information. If they cannot do it, who can or will? It is the same situation as a parent confronts with sex education" (p. 17). Sixtysix percent of respondents said everyone in their organization receives the code and $33 \%$ reported that middle and top managers receive it.

Penalties of violating the code included termination $(52 \%)$, suspension (30\%), demotion (19\%), probation (21\%), appraisal comments (14\%), and other penalties $(11 \%)$. They do not discuss the manner in which these codes are communicated to employees or comment on language and tone.

Matthews (1987) performed the most extensive content analysis using 64 topics in 202 Fortune 500 codes. She, like Cressey and Moore, categorized each topic as "not discussed", "discussed", "discussed in detail", or "emphasized." Results showed firms emphasized employee misconduct against the firm and illegal activities and spent little time talking about quality, product safety, and the environment. Matthews attempted to correlate ethical codes with corporate misconduct (i.e. corporations accused of illegal activity by federal agencies) and found only a weak link between ethical codes and corporate behavior. She found that codes did not provide selfregulation, demonstrate social responsibility, and promote a culture of ethical behavior. There is no 
discussion in this study about how codes are communicated. Regarding the second question of enforcement, the vast majority of codes did nor mention specific reprisals such as reprimands, fines, demotion, or dismissal as penalties for illegal behavior. About 25\% discussed legal prosecution. Matthews does not focus on linguistical dimensions in the codes.

Pitt and Groskaufmanis (1990) report the results of two ethical code surveys conducted by their law firm. ${ }^{3}$ Like other studies cited in this paper, they do not address whether the code has the personal endorsement of a CEO. However, $90 \%$ of their respondents in their 1987 survey $^{4}$ acknowledged having a code and $87 \%$ responded affirmatively to the question asking if the code was "widely known" among employees. Interestingly, none of the other studies asked this question. It addresses the extent to which the code has been communicated throughout the organization. If an ethical code is buried inside a policy book, it may not be read with great care by the employee. Also, if an organization has a code, yet few employees are aware it exists, the responsibility of the organization to fully and effectively communicate ethical policies may not be fulfilled.

With regard to the second question of enforcement and violation implications, $68 \%$ of respondents reported they had terminated an employee for a code violation and $11 \%$ noted that the code had become an issue in litigation with the firm. Thirtytwo percent asserted they had formal enforcement measures for their code and $79 \%$ stated that the code was effective in either ensuring or enforcing appropriate behavior.

Ethical codes are not unique to the United States. Schlegelmilch and Langlois (1990) report that numbers of European codes grew in the mid-1980's, but not to the extent found in the US. Their survey of 200 of the largest German, British, and French companies showed that the Germans have the greatest number of corporate codes $(51 \%)$ followed by the British ( $41 \%$ ), while only $30 \%$ of French firms surveyed have codes.

In comparing these with American codes, they found that American codes discuss both government and customer relations more extensively than do European and British codes. Additionally they report almost all codes in their study address employee conduct in contrast with only $55 \%$ of American codes. ${ }^{5}$ This underscores some of the complexity encountered in comparing these studies. "Employee conduct" was not chosen as an umbrella category in the studies cited although Chatov's "extortion, gifts, and kickbacks" or White and Montgomery's "misuse of corporate assets" or Pitt and Groskaufmanis's "misuse of confidential information" certainly refer to employee conduct. Thus, when we try to compare results across studies, it becomes a difficult task and some confusion is inevitable.

Except for reporting that 26\% of European and British firms restrict the codes to specific categories of employees, managers, or boards of directors, Schlegelmilch and Langois do not discuss the manner in which codes are communicated to employees. Code enforcement and implications for violations are also not discussed.

\section{Discussion}

Several rather interesting trends emerge from reviewing these ethical code studies. First, it is apparent that firms are strongly concerned with self-protection; that is, conflict of interest is a common theme in all nearly all the studies. Firms seem primarily concerned with employee misconduct which might damage the firm. Second, the codes seem preoccupied with following laws. While ethical codes should promote law-abiding behavior, it appears that they are preoccupied with law enforcement and selfdefense and often do not rise above this plateau to successfully articulate the values, beliefs, and precepts of a desirable corporate culture.

White and Montgomery, Chatov, Cressey and Moore, Sanderson and Varner, Chatov, and Slegemilch and Langlois all used content analysis to examine groups of codes. From White and Montgomery we learn that the most frequently mentioned subjects were acts against the corporation. Little information is given about how codes were communicated to employees, save that a high percentage of key officials were required to sign them. Language and tone are not discussed. Similarly, Chatov's content analysis provides information almost exclusively on code subjects and little on how the codes are communicated. His comments on "strong language" used in codes are particularly interesting, yet no additional details are given. Cressey and 
Moore focused primarily on code content rather than addressing effectiveness or communication efficacy; Matthews performed an extensive content analysis on codes and provided a rich body of information, yet language, tone, and how the codes are communicated was not discussed.

Are corporate codes effective? We lack solid evidence to support this notion. If, by effective, we mean corporations with codes behave more ethically, only Matthews addressed this question writing... "it cannot be concluded that codes of ethics demonstrate either (1) social responsibility, (2) a corporate culture which promotes anti-criminal behavior patterns or (3) self regulation" (p. 128). Are corporate codes transformational messages? Do they effect change in significant ways providing managers with support and guidance for negotiating sticky wickets? Are they communicated to employees in ways which underscore the importance of ethical conduct and encourage altruistic behavior. Evidence exists, at least with teenagers, that codes may alter behavior. A recent USA Weekend survey reported that $29 \%$ of 13-18 years olds said they would cheat on a math test given the opportunity to view an "A" student's papent however only $13 \%$ said they would do so if they had signed a school pledge not to cheat (Ansley and McCleary, 1992).

Rather than focusing so extensively on code content, perhaps we need to spend more time evaluating corporate codes as messages. Most of the questions about how codes function as messages remain unanswered. If ethical codes are to be studied as messages intended to direct and motivate strong ethical behavior, we need to explore the more exegetic aspects of these texts and analyze their messages more rhetorically rather than relying so heavily on content analysis. Studies focusing on the effectiveness of codes are needed. Do they work? Also, are the codes communicated in meaningful ways? Are employees aware of their organization's ethical code and accepting of its guiding principles.

Studies done thus far have shed some light on the subjects corporations consider important and laid an important foundation for further work. Codes, as expressions of values, are an integral part of corporate ethics. We need to focus more intensely on the effectiveness of these messages and analyze how codes use language to express values and beliefs.

\section{Notes}

For a historical discussion of professional codes in the legal, medical and accounting professions, see Backof, $\mathrm{J}$ and Martin, C (1991). Historical Perspectives: Development of the Codes of Ethics in the Legal, Medical and Accounting Professions. Journal of Business Ethics 10,99-110.

2 The Flesch Reading Ease Scale involves (1) averaging the number of words per sentence and multiplying that number by 1.1052 ) figuring the average number of syllables per word and multiplying by 0.8463 ) adding the two numbers together, then subtracting the total from 206.835. This yields a number between zero and one hundred. Zero is considered very difficult and 100 is considered very easy.

3 The law firm of Fried, Frank, Harris, Shriver and Jacobson, located in Washington, D. C., conducted the studies referred to as the Fried, Frank surveys in the Pitt and Groskaufmanis (1990) article.

4 The Fried, Frank 1984 survey received 121 responses from the 500 companies they contacted $(24.7 \%)$. In 1987,150 of 414 companies responded (36.2\%).

s Slegemilch and Langlois compared their data with the Foundation of the Southwestern Graduate School of Banking's 1980 "Study of Corporate Ethical Policy Statements."

\section{References}

Ansley, L. and K. McCleary: 1992, August 21-23, 'Ethics at Work: Help Wanted', USA Weekend, 5.

Becker, H. and D. Fritzche: 1987, 'Business Ethics: A CrossCultural Comparison of Manager's Attitudes', Journal of Business Ethics 6, 289-295.

Bennett, A.: 1988, July 15, 'Ethics Codes Spread Despite Skepticism', The Wall Street Journal, 17.

Berenbeim, R. E.: 1987, Corporate Ethics (Conference Boatd, New York).

Black, H. C.: 1983, Black's Law Dictionary (abridged 5th edition) (West, St. Paul).

Brooks, L. J.: 1989, 'Corporate Codes of Ethics', Journal of Business Ethics 8, 117-119.

Chatov, R.: 1980, 'What Corporate Ethics Statements Say', Californio Management Review 22(4), 20-29.

Cressey, D. and C. A. Moore: 1983, 'Managerial Values and Corporate Codes of Ethics', California Management Review 25, 53-77.

Frankel, M.: 1989, Professional Codes: Why, How, and With What Input?', Journal of Business Ethics 8, 109-115.

Heermance, L. Edgar: 1924, Codes of Ethics (Free Press, Burlington, $\mathrm{Vt}$ ).

Langlois, C. C. and B. B. Schlegelmilch: 1990, 'Do Corporate Codes of Ethics Reflect National Character? Evidence 
from Europe and the United States', Journal of International Business Studies, fourth quarter, 519-539.

Matthews M. C.: 1987, 'Codes of Ethics: Organizational Behavior and Misbehavior', Research in Corporate Social Performance, vol. 9 (JAI Press Inc, Greenwich, CT), pp. $107-130$.

Pearce, J. A. and F. David: 1987, 'Corporate Mission Statements: The Bottom Line', Academy of Management Executive 1(2), 109-116.

Pitt, H. L and K. A. Groskaufmanis, 1990, Minimizing Corporate Civil and Criminal Liability: A Second Look at Corporate Codes of Conduct', The Georgetoun Law Jotirnal $78,1559$.
Rogers, P. and J. Swales: 1990, 'We the People? An Analysis of the Dana Corporation Policies Document', The Journal of Business Communication 27(3), 293-313.

Sanderson R. and I. I. Varner: 1984, 'What's Wrong with Corporate Codes of Conduct?', Management Accounting $66,28-35$.

White, B. J. and R. Montgomery: 1980, 'Corporate Codes of Conduct', California Management Review, $13(2)$.

School of Business Administration, University of Michigan, Ann Arbor ML, 48108-1234,

U.S.A. 